\title{
A candidate's use of aggressive communication and the electorates' response: Predicting presidential election outcomes
}

\author{
Matthew Luke Sutton \\ West Virginia University
}

Follow this and additional works at: https://researchrepository.wvu.edu/etd

\section{Recommended Citation}

Sutton, Matthew Luke, "A candidate's use of aggressive communication and the electorates' response: Predicting presidential election outcomes" (2005). Graduate Theses, Dissertations, and Problem Reports. 793.

https://researchrepository.wvu.edu/etd/793

This Thesis is protected by copyright and/or related rights. It has been brought to you by the The Research Repository @ WVU with permission from the rights-holder(s). You are free to use this Thesis in any way that is permitted by the copyright and related rights legislation that applies to your use. For other uses you must obtain permission from the rights-holder(s) directly, unless additional rights are indicated by a Creative Commons license in the record and/ or on the work itself. This Thesis has been accepted for inclusion in WVU Graduate Theses, Dissertations, and Problem Reports collection by an authorized administrator of The Research Repository @ WVU. For more information, please contact researchrepository@mail.wvu.edu. 
A Candidate's Use of Aggressive Communication and the Electorates' Response: Predicting Presidential Election Outcomes

\author{
Matthew Luke Sutton \\ Thesis submitted to the Eberly College of Arts and Sciences \\ at West Virginia University in partial fulfillment \\ of the requirements for the degree of
}

\author{
Master of Arts \\ In \\ Communication Theory and Research
}

Theodore A. Avtgis, Ph. D., Chair Matthew M. Martin, Ph. D.

Keith Weber, Ed. D.

Department of Communication Studies

Morgantown, West Virginia

2005

Keywords: aggressive communication, elections, Presidential debates, verbal aggression 


\begin{abstract}
A Candidate's Use of Aggressive Communication and the Electorates' Response: Predicting Presidential Election Outcomes
\end{abstract}

Matthew Luke Sutton

The purpose of this examination is to determine the role of verbal aggression in Presidential debates. Using six types of verbally aggressive messages, coders examined one Presidential debate from nine Presidential elections to determine the amount of verbal aggression used by each candidate. The findings from this examination indicate that there is a pattern for the use of verbal aggression in Presidential debates. Challengers use significantly more verbal aggression than incumbents while five of the nine elections had the winner using less verbally aggressive messages than the loser. Results of this study support the theory that challengers are forced to go on the attack and use verbal aggression more often than incumbents. Implications of the results and paths for further research are also offered. 


\section{ACKNOWLEDGEMENTS}

I would like to extend my appreciation to all those people who gave their time and support for the goal of completing this project and for their support throughout my entire Master's year.

To Dr. Avtgis: Thank you for taking a chance with me on this project. I could never repay you for all the hours and hard work you put into this study with me. I could never have completed this project without your support or guidance.

To Dr. Martin and Dr. Weber: Thank you for participating in this project with me. I know it took a great deal of time and energy that you did not have to extend. I will never forget your generosity.

To My Classmates: Thank you for your patience and words of encouragements throughout this process and congratulations on your accomplishments this past year.

To My Friends and Family: This experience would have been meaningless without your support. Thank you for being there for me this year and throughout my life. 
Table of Contents

I. REVIEW OF LITERATURE....................................................

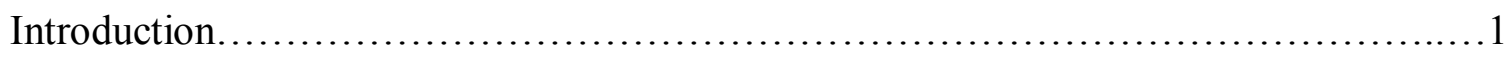

Argumentativeness/Aggressive Communication................................4

Persuasion..............................................................

Negative Campaigning as Verbal Aggression.................................... 8

Verbal Aggression as Enthymeme...........................................10

Electorate Expectancies of Verbal Aggressiveness and Argumentativeness..............12

Presidential Debates....................................................... 13

Purpose of Study....................................................... 14

Hypotheses......................................................... 14

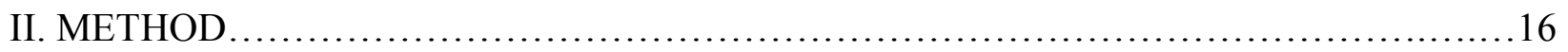

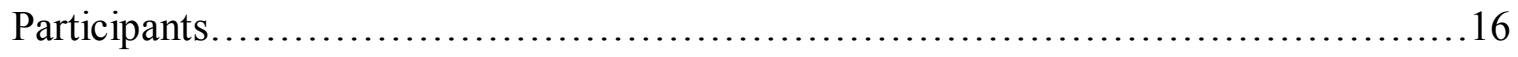

Procedures............................................................... 16

Instrumentation........................................................ 17

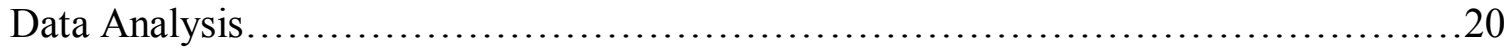

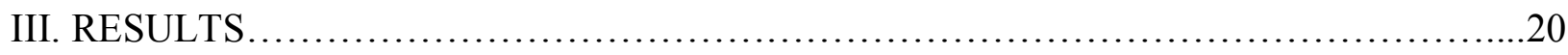

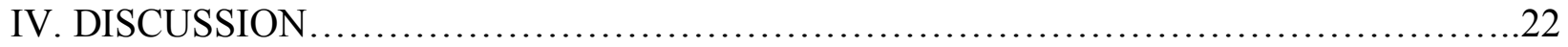

Limitations............................................................

Future Research.......................................................... 30

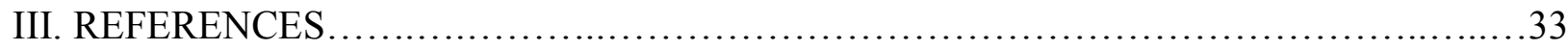

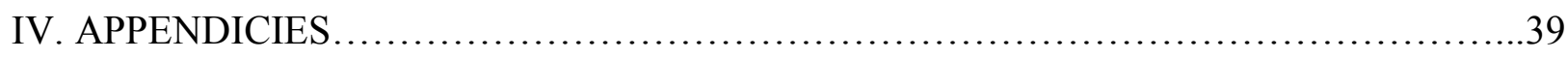

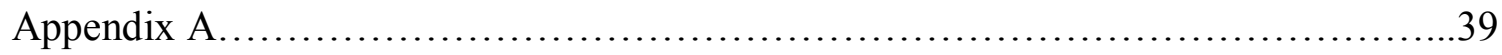


Appendix B......................................................... 40

Appendix C................................................................... 41

Appendix D.......................................................... 43

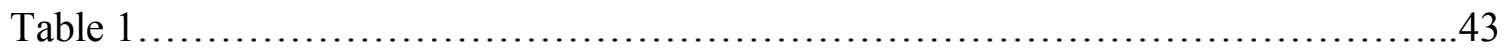

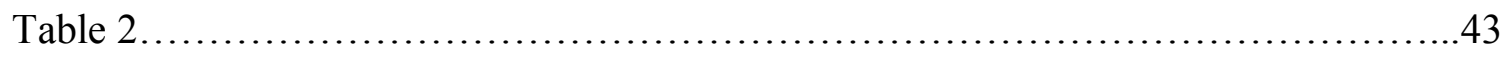

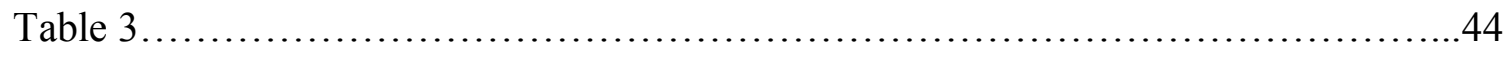

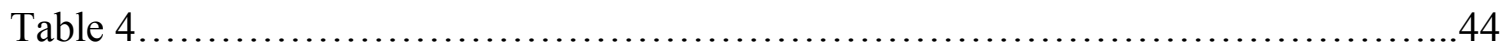

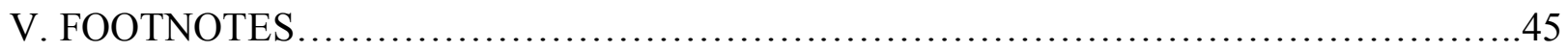


A Candidate's Use of Aggressive Communication and the Electorates' Response: Predicting Presidential Election Outcomes

\section{Review of Literature}

\section{Introduction}

There have been many attempts to create a model which accurately predicts presidential election outcomes. Most of these models are either mathematically based on message variables, some sort of economic indicators, or voter behavior. Markus (1992) as well as Nadeau and Lewis-Beck (2001) used national economic indicators as a way to predict presidential election outcomes. Markus (1992) dismissed the need for any specific campaign or even candidate, suggesting that the election of 1988 was going to a Republican no matter who ran. That is, regardless of incumbency, popularity, or issue debate, the Republican Party was going to win the election based on economic forecasts. Popkin (1994) suggested that it is the voters' ability to decode messages and gain information that will determine election outcomes.

While economic and voter based models have enjoyed some degree of success, source based models have been virtually ignored. Popkin (1994) determined that the message source is important only to the extent to which the voter is able to interpret the information. That is, voters start off with a limited amount of knowledge about candidates or policy positions. It is the campaigns job (i.e., candidate and campaign workers) to give the voters just enough information to get the voter to share their view. Lewis-Beck and Rice (1984) used popularity as a source indicator in employing their economy-popularity regression model for forecasting presidential elections and found that when combined with economic indicators, popularity has strong predictive powers in presidential elections. However, popularity is still voter centered, since it is 
the voters who create the popularity numbers. Miller and Shanks (1996) used bona fide source based characteristics when they examined the affects of a candidates personal traits, these were intelligence, inspiration, and compassion. All of these studies relied on voter perceptions of the candidate and not the candidates themselves (i.e., source focused). Although models for forecasting presidential elections have addressed measure and voter based characteristics, few have looked at the way in which the messages delivered by candidates affect the outcome of an election.

Benoit (2004) demonstrated that when it comes to winning elections, a candidate who attacks policy issues has a greater chance of winning than those candidates who attack their opponent's character. This suggests that negative campaigning is disliked by the voters. This is not the case when it comes to a voter's behavior, as evidence indicates that attack campaigning does in fact increase voter turnout and voter issue awareness (Wattenberg \& Brians, 1999). The difference in perception lies in the fact that attacks must be seen by voters as fair. When this perception is obtained, the voters will not be turned away from the polls (Faucheux, 2002). The question then concerns how candidates go about crafting attacks that appear to be fair while at the same time getting their point across and allowing voters to fully understand what is intended by their attack.

The most common attacks by candidates are targeted toward their opponents and are considered verbal aggression. For example, in the 1988 Vice Presidential debate, Lloyd Bentsen, vice presidential candidate for the Democratic Party, quickly reminded Dan Quayle, incumbent Vice President for the Republican Party, that he was "no Jack Kennedy." This is an example of a character attack, as defined by Infante, Riddle, Horvath, and Tumlin (1992). Bentsen, instead of arguing the facts or the point, quickly resorted to the use of verbal aggression to come back at 
Quayle knowing that it would be dramatically more effective that any logical fact or point focusing on an issue. Verbal aggressiveness is derived from the literature on hostility, and has been shown to be a negative communication trait (see Infante \& Rancer, 1996). Instead of employing a personal attack on an opponent, candidates can choose to argue the fact or issue. This would be an example of a candidate using argumentativeness instead of verbal aggressiveness. Debates are argumentative in nature, but attacks during the debates are done through the use of verbally aggressive utterances relayed by candidates.

Bentsen could have called Quayle stupid. However, this would have been the type of verbally aggressive message that Faucheux (2002) would categorize as unfair and therefore the message would turn away voters. What Bentsen did was use the verbally aggressive message in a strategic way. More specifically, he chose to use a type truncated syllogism known as enthymeme. This type of syllogism used by political candidates in order to employ attack messages while at the same time maintaining the public perception of fairness. Bentsen allowed the audience to conclude what he meant by his statement and allowed them to draw their own conclusions about Quayle. If negative campaigning from the candidate is to work, it must be hidden in the form of a strategic message (Faucheux), more specifically, the use of enthymeme as a tool for delivering the verbally aggressive message.

The current study examined the affects that the use of verbally aggressive utterances have on presidential candidate ability to get elected. Using the written transcripts and video taped presidential debates since 1960, it will be determined whether a candidate's ability to reduce his or her use of verbal aggression does impact the outcome of the election. Through this, it was determined that the use of verbal aggressiveness is prominent in the political arena and the use of verbal aggression in Presidential debates does impact the outcome of elections. 


\section{Argumentativeness/Aggressive Communication}

The development of the argumentativeness and verbal aggressiveness constructs stem from two doctoral dissertations from Kent State University. Infante and Rancer (1982) defined argumentativeness as "a generally stable trait which predisposes the individual in communication situations to advocate positions on controversial issues and to attack verbally the positions which other people take on these issues" (p. 72). The concept of argumentativeness is issue focused, meaning that the concept in concerned with a person's ability to argue and debate. Infante and Wigley (1986) defined verbal aggressiveness as "a personality trait that predisposes persons to attack the self-concepts of other people instead of, or in addition to, their positions on topics of communication" (p. 61). Verbally aggressive messages are aimed to attack an individual's selfconcept and can be seen as character attacks, competence attacks, ridicule, profanity, and nonverbal messages (Infante \& Wigley).

Aggressive communication is an interpersonal trait, meaning that the verbal aggression is sent by one person and is received by another. In order for a verbally aggressive message to be classified as verbal aggression, the receiver must view the message as an attack on his or her own self-concept (Infante, 1987). Perception is a key component to verbal aggression (Infante, 1987). In a debate context, verbal aggression may occur, but the impact of that aggression on the perceptions of the electorate would only occur if the audience interprets the aggressive message from the candidate to be an attack on the self concept of the other.

Verbal aggression can occur for many reasons. One of the reasons is the argumentative skills deficiency explanation (Infante, Trebing, Shepherd, \& Seeds, 1984), which suggests that individuals use verbal aggression because they are not skilled in the act of argumentation. In a 
Presidential debate, the argumentative skills deficiency explanation probably would not be supported, as both candidates are most likely skilled and coached in oratory and forensics. Another explanation for the use of verbal aggression in a Presidential debate could be candidate frustration. Frustration can lead to verbal aggression (see Infante, 1987). This is especially true in a debate situation. Consider a candidate who feels as if he or she is inferior when it comes to debating skills, this perceived deficiency may result in the attacking of the opponent's selfconcept as opposed to attacking the opponent's stance on issues.

The literature that examines the difference between argumentativeness and aggressive communication has shown that in almost every situation it is better to be argumentative than verbally aggressive. Argumentativeness has been found to be a positive communication skill in relationships while verbal aggressiveness is a determent to relationships (see Infante \& Rancer, 1996). This has been shown in a variety of contexts. For example, Rogan and La France (2003) determined that there was a negative relationship between verbal aggressiveness and concerns about relational goals during conflicts. In the family context, Beatty, Zelley, Dobos, and Rudd (1994) determined that a father's verbal aggressiveness influenced their adult sons' perceptions of sarcasm and criticism. In the organizational context, Infante and Gorden (1985) found strong evidence to support the claim that those subordinates who worked for superiors who were high in argumentativeness and low in verbal aggressiveness had higher job satisfaction. Regardless of the context, research indicated verbal aggressiveness could lead to physical violence, while argumentativeness may serve as a deterrent to physical violence (see Infante \& Rancer, 1996). For example, Infante, Chandler-Sabourin, Rudd, and Shannon (1990) found that violent marital disputes can be best predicted by the couple's level of verbal aggressiveness. In the group context, Anderson and Martin (1999) found support for a negative relationship between verbal 
aggressiveness and the communication satisfaction and consensus amongst group members. In all of these examples, verbal aggressiveness is seen as a negative communication skill and can be a detriment to the person using this behavior as well as to the relationship.

More recently there has been a push for more training in the use of argumentative communication. Rancer, Whitecap, Kosberg, and Avtgis (1997) recently found that adolescents could increase their trait argumentative as well as improve their ability to argue if trained using the Infante (1988) Inventional System. Students, after training, were able to determine the difference between verbally aggressive messages and argumentative messages after the training (Rancer et al., 1997). As much as a year later the level of trait argumentative remained the same (Rancer, Avtgis, Kosberg, \&Whitecap, 2000). This type of effort has also be used to reduce verbal aggression in adolescent populations (Meyer, Roberto, Boster, \& Roberto, 2004).

The ability to be argumentative can be a great asset for politicians, while verbal aggressiveness can have disastrous effects. Benoit (2004) demonstrated that when political candidates are issue focused they are received better by the public than those candidates who are person focused (e.g., attacking a person's character). Downs, Kaid, and Ragan (1990) indicated that in a 1988 interview with Dan Rather, President George Bush's use of verbal aggression negatively affected his communicator image. This demonstrates that the use of verbal aggressiveness can have a significant impact on a political figure's public image.

One of the key elements to making a successful run at the presidency is candidate image and a major component of candidate image is candidate credibility (Flanigan \& Zingale, 2002). It has been determined through the literature that high argumentatives are more credible than those who are low in argumentativeness and high in verbal aggressiveness (Rancer, 1998). Further, Richmond, McCroskey, and McCroskey (1989) found that high argumentatives score higher on 
the competence dimension of credibility, while Onyekwere, Rubin, and Infante (1991) found that both dispositional and situational determinants of communication competence were predicted by an individual's level of argumentativeness. Infante, Hartley, Martin, Higgins, Bruning, and Hur (1992) found an inverse relationship between verbal aggressiveness and credibility. Along with being seen as more credible, high argumentatives are also seen as more trustworthy (Rancer, 1998). This is due to the fact that the high argumentative person is seen as more sincere and the information the person presents is seen as more dependable.

Verbally aggressive attacks are not always seen as being harmful to an individual's credibility (see Infante \& Rancer, 1996). Downs, et al. (1990) found that, in the interview with Vice President George Bush, viewers saw Dan Rather's use of verbal aggression as acceptable, because Vice President Bush had attacked Rather first. If, as is suggested later, the use of verbally aggressive messages is strategic in Presidential debates, then a candidate could actually increase their credibility if he or she was to refrain from verbally aggressive utterances until they were attacked first. Thus, using verbal aggression as a strategic tool.

\section{Persuasion}

When it comes to political campaigns, effective persuasion determines how candidates gain support. At an aggregate level, voters have very limited information about politics, political ideology, political issues, and candidate position on issues (Popkin, 1994). If individuals possess little information about the candidates, then they will be more susceptible to persuasion (Popkin, 1994). Therefore, it is the goal of any campaign as well as the individual candidate to persuade the voters. One way campaigns go about persuading voters is to bombard them with a large amount of information on the fewest topics possible (Popkin, 1994). Persuasion is the process where a person's attempts to change another person's attitudes or behaviors (Perloff, 2003). The 
way the message is delivered profoundly affects whether or not the message received has the intended impact.

Major differences between argumentativeness and verbal aggressiveness have been evidenced when examining a person's ability to persuade others. Kazoleas (1993) found that high argumentatives are less persuadable, they are better at generating counterarguments and those arguments are more likely to be of higher quality then those that come from low argumentatives (Onyekwere et al., 1991). Onyekwere et al. also found that high argumentatives are more credible persuaders. When examining the receiver, Levin and Badger (1993) found that an argumentative person would tend to create more persuasive arguments when that person agrees with the persuader's stance. The majority of the literature points to verbal aggressiveness as hindering a person's ability to be persuasive (see Infante \& Rancer, 1996) Negative Campaigning as Verbal Aggression

In 1992 an average of 66 million people watched each of the three presidential debates between William Jefferson Clinton and Herbert Walker Bush (Holbrook, 1996). Jamieson and Birdsell (1988) suggested that there are different types of information a voter can receive when watching the debates. These are policy differences, party differences, character issues, and potential insight into the prospective presidencies. Candidates relay these messages in a variety of ways. One such way is through the use of strategic verbal aggression. Again, should a candidate personally attack another candidate in the same way we witness verbally aggressive attacks in everyday life, the candidate could be committing political suicide. Candidates are held to a higher standard and therefore must be more strategic in the encoding and delivery of aggressive messages. 
Candidates have gotten very good at using verbally aggressive messages during debates, without seeming likely they are attacking their opponents self-concept. In the 1984 Democratic Primary debate, Gary Hart was attacked for his lack of substance in the campaign. More specifically, Walter Mondale quipped at Hart with the line "Where's the beef" (Popkin, 1994). Mondale was using a verbally aggressive message to attack Hart's competence and his character. This attack worked well and the line "Where's the beef" stuck in the minds of the voters. As such, Mondale eventually went on to win the nomination, though not solely on the bases of verbally aggressive messages. This is an example of how strategic verbally aggressive messages are effective when they are not perceived as mean spirited.

Verbally aggressive messages can be effective when used correctly or strategically and deemed to be "fair" by the voters. However, these messages can backfire on a candidate if used incorrectly or deemed unfair. In the first debate of the 2000 presidential election, $\mathrm{Al} \mathrm{Gore,} \mathrm{the}$ democratic nominee for president, sighed and moaned numerous times during times when George Bush, the Republican nominee was speaking. Bush went on to defeat Gore. This occurred again in the first debate of the 2004 election. Bush, who was the incumbent this time, sighing, moaning, and making negative facial expression while John Kerry, the democratic challenger, was talking. The damage done to Bush was minimal as he was re-elected. Both of these are examples of nonverbal verbal aggression and hurt each candidate to the point of the incident partially being attributed to the candidate losing or coming close to losing the debate.

The literature on argumentativeness and verbal aggressiveness has covered many aspects of the receiver, the source, and message factors. One area in which the research has seemingly ignored is the effects of aggressive communication in the political field. Downs, et al. (1990) examined the use of argumentativeness and verbal aggression in an exchange between then Vice 
President George H. Bush and Dan Rather. Their results showed that both verbal aggressiveness and argumentativeness had an impact on communicator image and that Vice President Bush's verbal aggressiveness negatively affected his image (Downs et al., 1990). Bush went on to lose the presidential election to Clinton in 1992. This research shows that communicator style and aggressive communication does impact the way in which we look at public officials. Just recently, Benoit (2004) demonstrated that a candidate who attacks an opponent's character can negatively affect voter perceptions of his candidacy.

Although, research has been conducted concerning candidate behavior during presidential debates, no study has utilized the argumentative and verbal aggressive constructs as a way to assess debate outcomes. Pervious conceptualizations used the terms mud slinging, negative attacks, or character attacks. All of these behaviors and utterances fall under the definition of verbal aggressiveness (Infante \& Wigley, 1986) and need to be categorized as such. One of the main reasons that these attack utterances are not called verbal aggression is because the candidates do a good job of hiding them with the use of enthymeme.

\section{Verbal Aggression as Enthymeme}

The research in the political field has not conceptualized the strategic use of verbal aggressiveness as enthymeme. Instead, the political field has focused on attack message and negative campaign strategies. Pfau and Burgoon (1989) examined the efficacy of attack messages and determined that issue attack messages exert more change in voter choice than character attacks. Cobb and Kuklinski (1997) have shown that negative messages work in persuading public opinion and political awareness. Research has suggested that not all negative campaigning is bad, though the moral criteria for these attacks need to be judged (Mayer, 1996). What the research fails to recognize is that inherent in attacks on policy or issue stance and 
negative campaigning are verbally aggressive messages. Political candidates cannot overtly verbally abuse their challenger for the obvious implication of being perceived as mean spirited or unfair. Instead they do this through the use of enthymeme.

An enthymeme has been defined as "premises which members of the audience supply if they were to proceed by question and answer" (Bitzer, 1959, p. 408). Put simpler, an enthymeme is a statement in which the speaker allows the audience to come to their own conclusions. Zulick (1997) stated that an enthymeme is "merely a kind of short saying with a contrary or refutative character" (p. 114). When examining the "enthymeme gap" in the 1996 presidential campaign, Jamieson, Falk, and Sheer (1999) stated that an enthymeme functions "by suppressing premises that are then filled in by members of the audience. Out of this complicity come conclusions whose impact is heightened by audience participation in their construction" (p. 13). Persuasion research clearly shows the heighten efficacy of messages when the audience is involved in the processing of the message (Petty \& Cacioppo, 1986).

Enthymemes are constructed to include common opinions about advantage, justice, and nobility along with the passions of men and the elements that form their character (Nichols, 1987). Guerrero and Dionisopoulos (1990) believed that enthymemes are undoubtedly effective because the audience members are the ones who fill in the missing pieces, therefore the logic makes sense to them. Jackson and Jacobs (1980) contended that enthymemes are inherent in conversation because most arguments that are made in conversation are incomplete. The underlying contention in enthymemes is stated by Jackson and Jacobs (1980): "be as informative as necessary for the purposes of agreement, but avoid being more informative than is necessary" (p. 263). Herein lies the strategic nature of verbal aggressiveness. A candidate needs to supply enough information about the other candidates' character, competence, and other personal 
characteristics, but not so much as to be seen as mean spirited. For example, in the 2004 presidential debates, Bush kept referring to Kerry as a "flip-flopper" when it came to his perceived changing of positions on a variety of issues. The "flip-flopper" label let the voters conclude that Kerry could not be trusted to be secure in his issue stances. Bush was strategically attacking Kerry's character, without saying that Kerry could not be trusted.

\section{Electorate Expectancies of Verbal Aggressiveness and Argumentativeness}

When the use of enthymeme is examined in presidential elections and debates, it is clear that the enthymematic process is not only engaged, but the candidate is put in a position where he or she is rewarded for using them effectively. Aden (1994) argued that the media forums used generally preclude extended lines of questioning which leaves the mediator, interviewer, or audience little ability to respond to the unsaid and underlying. Further, voters know that public officials are not inclined to answer further questions and therefore the voters do not expect any future clarification (Aden, 1994). Jamieson et al. (1999) demonstrated that when looking at advertisements during the 1996 presidential election, it was clear that the Democratic Party was sending hidden messages in their advertisements. For example, some ads showed families and children, which was aimed to getting women to identify with the party (Jamieson et al., 1999). Incumbents have a clear advantage when it comes to the expectancies of the voters. Incumbents are allowed to attack their opponents and paint them as risks because of the lack of information voters receive (Popkin, 1994). This allows incumbents to get away with more direct attacks, albeit no overt, then a challenger might be allowed to. It has also been found that since incumbents are usually the early frontrunner in an election, the challenger will be forced to go negative or resort to character attacks more often than the incumbent will (Skaperdas \& Grofman, 1995). 
One of the keys for candidates to avoid being perceived as mean spirited is to allow political operatives to do the overt verbal aggressive attacks for them. James Carville, democratic political strategist and Tucker Carlson, a conservative political analyst, can attack and argue about the issues and candidates without having to uphold any type of candidate image. People in this position are allowed to be mean spirited because this is what the public expects from them. This is how candidates can attack the character and competence of their opponent while maintaining a perception of "fairness."

In most presidential election studies, character and credibility of the candidate are eventually factored in (Popkin, 1994). The electorate forms its own opinion of a candidate's character through various means. These include role call votes, positions on issues, personal life, issues, and success in past elections (Popkin, 1994). Character and credibility are essential if a candidate hopes to get elected. It has been demonstrated that verbal aggressiveness hurts a person's credibility (see Infante \& Rancer, 1996). Therefore, candidates must do their best to use strategic verbal aggression without seeming like they are personally attacking their opponent.

\section{Presidential Debates}

Presidential debates have become the cornerstone to the modern Presidential campaign and can affect the outcome of an election. Benoit, Hansen, and Verser (2003) suggested that Presidential debates do alter voters' perceptions of a candidate's personality, which can affect their vote choice. Most research that has been conducted on Presidential debates, employs the functional theory (Benoit, Blaney, \& Pier, 1998), which states that citizens determine their vote choice based on policy and character (i.e., personality and competence). Debates have been found, through the use of the functional theory, to increase voter confidence in their vote choice (Benoit, McKinney, \& Holbert, 2001), provide information about candidates upon which vote 
choices are made, affect vote preference, and increase knowledge and issue salience (Benoit, et al., 2003). Presidential debates have been found to provide an opportunity for voters to learn about candidates and for candidates to publicly address the voters in an attempt to gain their vote (see Benoit, et al., 2003).

Purpose of Study

Based on what is already known about the negative affects of verbal aggressiveness and the detrimental influence on everyday life, this study attempts to show that even though the terms are not used, the idea that verbal aggressiveness is destructive to people's image is equally important in the political realm as well. In this vein, an examination of verbally aggressive utterances during the presidential debates was conducted to determine the effect that the use of these utterance have on a candidate's ability to get elected. There was also an examination of what type of candidate (i.e., incumbent or challenger) used more verbally aggressive utterances and how the use of those messages impacted each candidate's ability to get elected.

\section{Hypotheses}

It is well documented that the challenger in a presidential debate is often on the offensive with regard to questioning and criticizing the incumbent ${ }^{1}$ (Popkin, 1994). Moreover, this offensive usually takes the form of attacking the record of the incumbent. Knowing that the challenger must attack the record of the incumbent, most time these types of attacks take the form of aggressive utterances. Skaperdas and Grofman (1995) stated that since the challenger is usually forced to come from behind, it is the challenger that would go negative more often. Even though the incumbent can, and often does, go on the attack, incumbents generally spend the majority of their time defending their record and less time attacking the opponent (Popkin, 1994). Therefore, the following hypotheses were forwarded: 
H1: In each debate, the challenger will have more verbally aggressive utterances than the incumbent.

$\mathrm{H} 2$ : Throughout all the debates, the challengers use more verbally aggressive utterances than the incumbents.

H3: Incumbents who lose the elections will have used more verbally aggressive utterances than challengers who won the elections.

Research indicates that people who use large amounts of verbal aggression are seen to be less credible and less persuasive (see Infante \& Rancer, 1996). Given that character and credibility are two of the main factors voters use in determining whom they will vote for (Popkin, 1994), and that verbal aggression serves as a detractor from credibility, the candidate who uses greater amounts of these utterances will not be received well by the public. Therefore, the final two hypotheses were forwarded:

H4: The candidate, regardless of challenger or incumbent, who uses the fewest amounts of verbally aggressive utterances in each debate, will be the winner of the election. H5: Throughout all the debates, the winners of the elections will use less verbally aggressive utterances than the losers.

For four of the nine Presidential debates, video copies were also coded in order to determine if there is an impact of nonverbal verbal aggression. Therefore a research questions was postulated:

RQ1: Is there a difference between the number of verbally aggressive utterances that are coded using the transcript versus the video copy. 
Method

\section{Participants}

Coders were ten undergraduates who excelled at the top of their of their undergraduate research methods course (i.e., Comm 201). The coders were six men and four women with an average age of 21.4 years $(S D=1.65)$. Of these there were three Democrats, four Republicans, two Independents, and one that was not registered. Of those registered, six voted in the 2004 Presidential Election.

\section{Procedures}

Coders attended a training session where they were trained in the recognition of and proper classification of verbal aggression using the taxonomy developed by Infante and Rancer (1982). Before participating in the training session, each coder completed the short version of the Infante and Rancer (1982) Argumentativeness Scale (see Appendix A), the short version of the Infante and Wigley (1986) Verbal Aggressiveness Scale (see Appendix B), and a set of demographic questions consisting of political ideology and information about their viewing patterns of the three 2004 Presidential debates (see Appendix C).

Following the training session, each coder was given the transcript for a practice debate (i.e., vice presidential debate from 2000) to determine if future training was necessary. To determine if the training session was successful, the percent of agreement on the coder's transcript copy with the master copy of the debate transcript was calculated (the master copy was completed by the researcher). Seventy-eight percent agreement was found for determining if verbal aggression had occurred and 71\% agreement was found for matching the specific types of verbal aggression (i.e. blame, character attack, competence attack, personality attack, and other). 
Since the percentage of agreement was greater than $70 \%$, training was considered to be successful (see, Frey, Botan, \& Kreps, 2000).

After coding consistency was achieved, each coder was given a transcript of one debate from each presidential election. Each coder was provided the same debate, which was chosen at random for each election cycle. The presidential debates included in the analysis were originally transcripts and televised presidential debates starting with Kennedy-Nixon (1960) and ending with Kerry-Bush (2004). However, televised copies of the debates were obtained for four of the nine races. ${ }^{2}$ Once the transcript portion of the project was completed, the coders viewed a video copy of the same debate. ${ }^{3}$ For each medium (i.e., written or televised) the coders labeled each utterance of verbal aggression based on the types of verbal aggression identified by the literature on verbal aggression. Infante, Riddle, Horvath, and Tumlin (1992) and Infante et al. (1990) identified ten types of verbal aggression: character attack, competence attack, background attack, physical appearance attack, malediction, teasing, ridicule, treats, swearing, and nonverbal emblems. Infante, Rancer, and Ambler (1994) later identified blame and personality attacks as other forms of verbal aggression. Of the types of verbal aggression identified from pervious literature, six were deemed appropriate for the political arena. These six were: blame, character attack, competence attack, personality attack, nonverbal emblem, and other. The types of verbal aggression that were not included in the present study were determined to be inappropriate for the political communication context (e.g. profanity).

\section{Instrumentation}

The coders were trained using six types of verbally aggressive utterances identified by Infante and Rancer (1982) (See Appendix E). The six types of verbally aggressive utterances were chosen based on their likelihood of being used in a Presidential debate (e.g. profanity was 
excluded as it has never be used in a Presidential debate). Though the use of these items have never been utilized in analyses of Presidential debates, these items have been used in various other studies (see Infante \& Rancer, 1996). For this study, each verbally aggressive message type was labeled one through six for coding purposes.

Previous literature has identified several types of verbally aggressive message types (Infante et al., 1994; Infante et al., 1992; Infante et al., 1990). Six were deemed appropriate for the political communication context. Blame is categorized as the singling out of a person for fault in a major problem. Competence attacks are verbal attacks of another person's intellect, capability, or ability in dealing with a specific situation. When a person attacks another as having a lack of character, a character attack has occurred. Personality attacks occur when a person attacks another's personality or traits. Nonverbal verbal aggression is instances of negative facial expressions, gestures, or other nonverbal occurrences. The Other category is used to categorize utterances that do not readily fit clearly into any one of the previous categories.

The Argumentativeness Scale (Infante \& Rancer, 1982) is a 20-item scale measuring an individual's general tendency to engage in argument. Ten items measure motivation to approach argumentative situations and 10 items measure motivation to avoid argumentative situations. Respondents are asked to fill out the instrument using a 5-point Likert type format, ranging from almost never true (1) to almost always true (5). Reliabilities have typically ranged between .80 and .90 for this scale (see Infante \& Rancer, 1996). The scale also appears to be stable across time (Infante \& Rancer, 1982). More recently, a short 10-item version of this scale has been used. For example, Venable and Martin (1997) used the 10-item version of this scale to measure the relationship between relationship satisfaction and a partner's use of argumentativeness. A reliability of .81 was reported for the study. For the current study, the 10 -item version of the 
scale was utilized. Due to the small sample size $(N=10)$ in this study, the internal consistency of the Argumentativeness Scale was not computed. Though no internal reliability was determined in this study, this scale has been used in numerous studies and found to be internally consistent (see Infante \& Rancer, 1996).

The Verbal Aggressiveness Scale is a 20-item scale measuring a person's tendency to engage in verbal aggression (Infante \& Wigley, 1986). Respondents are asked to fill out the instrument using a 5-poing Likert type format, ranging from almost never true (1) to almost always true (5). Reliabilities are usually reported in the low to mid .80s (see Infante \& Rancer, 1996) and the scale is also stable across time (Infante \& Wigley, 1986). More recently, a 10-item version of this scale has been used. For example, Rocca and McCroskey (1999) used the 10-item scale to measure the relationship between teacher immediacy and teacher verbal aggression and reported a reliability of .88 . For the current study, the 10 -item scale was utilized. Again due to the small sample size $(N=10)$ in this study, the internal consistency was not computed. However, this scale has been used numerous times and found to be internally consistent (see Infante \& Rancer, 1996).

Trait argumentativeness and trait verbal aggressiveness scores were collected from the coders to determine if there was a correlation between trait argumentativeness and verbal aggressiveness and their interpretation of verbal aggression use during the debates. Pearson Product correlations were computed. Results indicated no statistically significant findings between trait verbal aggressiveness and coding verbal aggression $(r=.55, p=-.22)$, as well as between trait argumentativeness and coding verbal aggression $(r=.13, p=.52)$. Therefore, the coders' trait levels of argumentativeness and verbal aggressiveness did not influence their coding, suggesting that the training was successful. 


\section{Data Analysis}

Each hypothesis was measured using Independent samples $t$-tests. Tests were computed for on each individual race for Hypothesis One and Hypothesis Four. Total mean $t$-tests were computed to test Hypothesis Two, Hypothesis Three, and Hypothesis Five. Research Question 1 was measured using an Independent samples $t$-test, as well. Means and standard deviations were created for each race (see Table 1). Point-biserial correlations were calculated for each Independent samples $t$-test to determine the variance accounted for.

\section{Results}

Hypothesis One postulated that in each of the debates, the challenger would have more verbally aggressive utterances than the incumbent. Overall, results of the independent samples $t$ tests indicated partial support for the hypothesis. In every race where there was statistical difference between the candidates' use of verbally aggressive utterances, the challenger used more verbally aggressive messages than the incumbent $(t=-6.87, p<.001)$. There were six races in which there was a statistical difference between the candidates' use of verbally aggressive utterances: Ford-Carter $(t=-4.43, p<.001)$, Carter-Reagan $(t=-2.23, p<.05)$, ReaganMondale $(t=-3.83, p<.01)$, Bush-Dukakis $(t=-4.99, p<.001)$, Clinton-Dole $(t=-3.20, p<$ $.01)$, and Bush-Kerry $(t=-4.13, p<.001)$. Table 1 lists the means and standard deviations for each candidate. Since there was one dichotomous variable (i.e., incumbent or challenger) that was correlated with a continuous variable (amount of verbal aggression) point-biserial correlation coefficients were calculated in an effort to determine the strength of the relationship between the variables (Glass \& Hopkins, 1970). Table 2 reports the results for the point-biserial correlations. In all but one of the races examined (i.e., Nixon-Kennedy) in this study, regardless 
of whether or not there was statistical significance, the challenger used more verbally aggressive utterances than the incumbent.

Hypothesis Two stated that when examining all of the debates, the challengers would use more verbally aggressive utterances than the incumbents. Results of an independent samples $t$ test showed a statistically significant difference between the challengers' use of verbal aggression $(M=44.88, S D=26.64)$ and the incumbents' use of verbal aggression $(M=23.04$, $S D=14.17)$ for all the debates combined $(t=-6.87, \mathrm{p}<.001)$. Therefore, Hypothesis Two was supported. The point-biserial correlation coefficient for this hypothesis was -.46, accounting for $21 \%$ of the variance.

Hypothesis Three predicted those incumbents who lost the election $(M=22.36, S D=$ 7.24) would have used more verbally aggressive utterances than the challengers who won the election $(M=32.28, S D=11.57)$. The results of an independent samples $t$-test did not support the hypothesis $(t=-3.06, p<.05)$. In examining all of the debates combined, there was a statistically significant difference between the incumbents who lost the election and the challengers who won the election. However this trend was in the opposite direction of that which was hypothesized. The point-biserial coefficient for this hypothesis was -.32 accounting for $10 \%$ of the variance.

Hypothesis Four claimed that the winner of each election would be the candidate who used the fewest amount of verbally aggressive utterances. In the six races where there were statistical differences between the number of verbally aggressive utterances used by the winner and the loser, four races supported the hypothesis. The four races that supported the hypothesis were: Reagan-Mondale $(t=-3.83, p<.01)$, Bush-Dukakis $(t=-4.99, p<.001)$, Clinton-Dole $(t=$ $-3.20, p<.01)$, and Bush-Kerry $(t=-4.13, p<.001)$. There were two races that did not support 
the hypothesis. However, they were still were statistically significant but in the opposite direction. These races were Ford-Carter $(t=4.43, p<.001)$ and Carter-Reagan $(t=2.23, p<$ .05). Therefore, results indicated partial support for the hypothesis. Table 1 lists the means and standard deviations for each candidate. Point-biserial correlation coefficients were calculated for each race. Table 3 shows the correlations and variance accounted. Regardless of statistical significance, only five of the nine races in the study had the winner using more verbally aggressive utterances than the loser.

Hypothesis Five stated that when examining all of the debates, the winners of the election would use less verbally aggressive utterances than the losers of the election. Results of an independent samples $t$-test showed a statistically significant difference between all winners $(M=$ 28.56, $S D=17.61)$ and all losers $(M=39.37, S D=27.97)$ when all the debates were combined $(t$ $=-3.10, p<.01)$. Therefore, Hypothesis Five was supported. The point-biserial coefficient for this hypothesis was -.23 , accounting for $5 \%$ of the variance.

Research Question One asked whether the type of medium used to code the debates for verbally aggressive utterances (i.e., written or video) impacted the number and type of coded verbally aggressive utterances. Results from an independent samples $t$-test comparing each candidate's number of verbally aggressive messages in the written transcript and the video transcript indicated that there were no statistical differences between the coding for the written transcript or video copy of the debates for all candidates.

\section{Discussion}

Despite numerous studies that have focused on the impact of the use of verbal aggression in society (see Infante \& Rancer, 1996), little research has examined the impact of the use of verbal aggression in the political communication field. Recently, Benoit (2004) investigated the 
connection between political campaign attacks and electoral success, but the focus was not on verbal aggression. The results of the current study add to both the field of research on verbal aggression and the impact of attack campaigns in the political communication literature.

The overall results of this study indicate that in a Presidential debate, the challenger will use more verbally aggressive utterances than the incumbent. The results also indicate that the winner of the election will use less verbally aggressive messages than the loser. This is not to say that the results of an election will be based solely on the use of verbally aggressive utterances in the debates, but that the use of these verbally aggressive messages do have an impact on the outcome of an election. Results of the current study also indicated a pattern has emerged which allows for challengers to win the election, while at the same time being more verbally aggressive than their incumbent opponent. Also found in this study was that the medium that is used to code Presidential debates for verbally aggressive messages does not differ. More specifically, there is no statistically significant difference between coding for verbally aggressive utterances using a transcript or a videotape copy of a debate.

Hypothesis One and Hypothesis Two examined the impact of a candidate's debate status (i.e., incumbent or challenger) on their use of verbal aggression. The results from both hypotheses suggest that challengers will use more verbally aggressive utterances than incumbents. Hypothesis One found that of the six races in which there was a statistically significant difference between the amount of verbally aggressive utterances used by the incumbent and challenger, all races had the challenger using more verbal aggression. The findings support the claims made by Skaperdas and Grofman (1995) that challengers are forced to go negative more often based on their position in the election. Popkin (1994) suggested that the reason challengers go on the offensive, or more negative, is because the challenger attacks 
the incumbent's record, forcing the incumbent to be defensive and avoid attacking the challenger. The results of this study support what Popkin was suggesting by demonstrating that the challenger will attack the incumbent using verbally aggressive messages and the incumbent will be forced to defend himself but not reciprocate the verbal aggression.

If the use of verbally aggressive messages are a destructive communication behavior (see Infante \& Rancer, 1996), then the incumbent should be at a distinct advantage. That being suggested, Hypothesis Three predicted that incumbents who lost the election would have used more verbally aggressive utterances than challengers who won. While this hypothesis was not supported, there was a statistically significant relationship in the opposite direction. The results indicated that incumbents who lost still used less verbally aggressive messages than the challengers who won. This finding has interesting implications. First, the results further support the claim that incumbents will use less verbally aggressive utterances simply because of their status in the election. Popkin (1994) found that incumbents are held to a higher standard because of their position as either a sitting President, or as a representative of the sitting President's party. The findings from this hypothesis provide further evidence that incumbents are indeed held to a higher standard and that they are aware of that standard going into a debate.

The second implication of this finding is that there must be a pattern for the use of verbally aggressive utterances for those challengers who are able to win elections. In this study, there were five of nine races in which the incumbent lost. While this study does not account for economic conditions or other variables that are usually found in typical election models, a pattern exists for challenger victory. While evidence in this study still supports the notion that the challenger is always expected to use negative tactics (Skaperdas \& Grofman, 1995), it appears that it is the degree in which they use those negative tactics that indicate victory or defeat. In this 
case, verbally aggressive utterances, against their opponent. The results of an Independent samples $t$-test found that the frequency of utterances used by the challenger can impact the outcome of an election. The results indicate that there is a statistically significant difference between the number of verbally aggressive utterances used by challengers who win and challengers who lose $(t=-3.04, p<.05)$. Challengers can go on the attack and appear to be allowed to use more verbally aggressive utterances than the incumbents.

Where challengers can cause harm to themselves is in the amount of verbally aggressive utterances they use. Along with frequency of verbal aggression, the types of utterances used appear to be an indicator of challenger success. The challengers who focus their verbally aggressive attacks on a blaming the President for negative outcomes, and not the President's character, have better success in the outcome of the election. The challengers who win the election used the verbally aggressive utterance of blame $31 \%$ of the time as compared to using character attacks $18 \%$, while the challengers who lost only used blame $20 \%$ of the time and character attacks $26 \%$ of the time (both groups used competence attacks approximately $50 \%$ of the time). This demonstrates that the electorate may be willing to tolerate a greater use of verbally aggressive messages by the challenger if they focus on the incumbent's record, while reducing the amount of verbally aggressive utterances that implicates the President's character. The results of this study further support Benoit's (2004) finding that winners of an election are more likely to attack policy and less likely to attack character, than election losers.

From the results of Hypothesis Three, there appears to be a clear pattern of success for challengers. It appears that if challengers are able to direct their verbal aggression at an incumbent's record then they will be successful as compared to when the challenger attacks the incumbent's character. This is evidenced in Hypothesis Four receiving partial support and 
Hypothesis Five only accounting for five percent of the variance. Hypotheses Four and Five suggested that the winners of the elections in general would have used less verbally aggressive utterances than the losers. Four out of the six statistically significant races supported Hypothesis Four, which predicted that in each individual race, the winner would use less verbally aggressive messages than the loser. The four races that did support the hypothesis further support the notion of verbal aggression being a destructive communication behavior (see Infante \& Rancer, 1996).

The four races, which supported the fourth hypothesis, occurred from 1984 to the most recent election, while the two, which do not support the hypothesis, occurred in 1976 and 1980. These elections also need to be framed in their historical surrounding in order to better understand the role of verbal aggression. It appears that as time goes on, the electorate is becoming less tolerant of the use of verbal aggression from their candidates. The study of verbal aggression as a communication construct did not begin until 1986 (Infante \& Wigley, 1986). The majority of the research conducted on the construct primarily occurred in the early 1990s and continues to garner attention from scholars (see Infante \& Rancer, 1996). Verbal aggression appears to be more prevalent in contemporary society. However, it appears that the tolerance of the electorate toward candidate use of verbal aggression is still rather modest. Verbal aggression in society appears to be more ubiquitous now as compared with the late 1970s and early 1980s. This is evidenced by recent literature on verbal aggression in the mass media that has examined sitcoms (Martin, Mottet, Weber, Koehn, \& Maffeo, 1998), family comedies (Martin, Koehn, Weber, \& Mottet, 1997), television dramas (Glascock, 2003), and professional wrestling (Tamborini, Chory-Assad, Lachlan, Westerman, \& Skalski, 2005).

Historical context was not the only factor in the two races that did not support Hypothesis Four. Since President Dwight Eisenhower, there was no President elected for a second term until 
1984. During this period incumbents either did not run (i.e., Johnson), or they lost (i.e., Carter). Neustadt (1990) suggests that the lack of presence of a two term President was a handicap for both Ford and Carter. In 1974, Ford was unable to recover from his connection to Nixon and the Watergate scandal, putting him at a disadvantage from the beginning (Miller \& Shanks, 1996). With Ford being doomed from the start, Carter appeared to only be a stopgap until 1980 when a more energetic, charismatic, and partisan Reagan emerged (Miller \& Shanks, 1996).

Erikson, MacKuen, and Stimson (2002) suggest that two other factors could have been at work during these two elections. During the 1976 election, policy mood on a measure of public opinion ranging from liberal-conservative continuum was at its highest liberal point. This was not achieved again until the early 1990s. High policy mood suggests that the country was leaning towards a more liberal President as a backlash to the Nixon administration. The backlash only appeared to last until 1980 when the mood chart reached its lowest point in history (i.e., increase in conservatism) (Erikson et al., 2002). The sudden shift in mood suggests that Carter was not going to be reelected in 1980 no matter how Reagan behaved during the debates. In 1980, the country had also reached it lowest point in history on the Ideological Self-Identification Scale (Erikson et al., 2002). The Ideological Self-Identification Scale measures the ideology of the public which is also based on a liberal-conservative continuum. In 1980 people had reached a period where they were at their lowest point of liberalism since the scale had been in effect (it is important to note that neither scale ever reaches conservatism, only less liberalism). These two scales in conjunction with one another suggested that Carter had no chance for victory in 1980. Therefore the public was willing to ignore Reagan's use of verbally aggressive utterances during the debates. 
It should be noted that while these race results do not support Hypothesis Four, the results do provide strong evidence that challengers will use more verbally aggressive utterances than incumbents. The fact that the challenger can, and does win, does not dismiss from the findings that the challenger will use more verbally aggressive utterances. The findings from Hypothesis Four indicate that there is a possibility for the winner of an election to use more verbally aggressive utterances, but it still holds that the challenger will use more verbally aggressive utterances. This finding supports the major implication of this study that demonstrates that challengers, regardless of their success in an election, will use more verbally aggressive utterances in the debates than the incumbents.

Hypothesis Five stated that in all the elections winners would use less verbally aggressive messages. Although this was supported there was a weak relationship between winning and the use of verbally aggressive utterances. Based on the results of Hypotheses Three and Four, these results are not surprising. It appears that while incumbents use less verbally aggressive message, challengers can compensate for their use of verbally aggressive utterances by only using a moderate amount of verbal aggression and choosing the correct type of verbally aggressive utterances to use. Blame appears to be the most suitable type of verbally aggressive utterance for challengers to use, while character attacks have been found to be more detrimental to the challenger. Further, successful challengers use blame significantly more than unsuccessful challengers. Another explanation for the findings between victory and the use of verbally aggressive utterances concerns the lack of accounting for historical events such as Watergate in 1976 and Iranian hostage crisis of 1980 (Miller \& Shanks, 1996; Neustadt, 1996) or major shifts in ideology and partisanism in 1996 and 2000 which may have had an effect (Erikson et al., 2002). 
In the present study, written transcripts and video taped debates were used as the media for which verbal aggression was coded. The purpose for this procedure was to see if there was any difference between coding a debate using a written transcript or viewing the actual debate. The main difference between the two mediums would be attributed to the use of nonverbal verbal aggression. Research Question One was attempting to determine whether the use of nonverbal verbal aggression impacted the debates enough to cause the written transcripts to be an ineffective way of coding for verbally aggressive utterances in the debates. The results of Research Question One indicate that the use of nonverbal verbal aggression does not impact the debates to the point where the transcripts are an inaccurate measure of verbally aggressive utterances. This is not to suggest that the use of nonverbal verbal aggression does not exist. What this does suggest is that the use of nonverbal verbal aggression is done carefully and strategically. Presidential candidates are carefully coached and trained on how to behave and act in public (Popkin, 1994). It appears that the same techniques are used in coaching a candidate to use nonverbal verbal aggression in the debates. Candidates use congruity to mask their use of nonverbal verbal aggression. When a candidate uses nonverbal verbal aggression they are usually doing so along with it complementing the verbal component. The use of aggressive hand gestures is a form of nonverbal verbal aggression, but a strong statement usually accompanies the use of hand gestures. Where the hand gestures being used emphasize the point of the verbal utterance to the audience. This supports the use of strategic enthymemes in Presidential debates, by demonstrating that candidates purposively use nonverbal verbal aggression to demonstrate the strength of their point to the audience.

The overall conclusions of this study find partial support for the notion that verbal aggression is a detrimental communication behavior. Previous research has mainly suggested 
that in most situations verbal aggression has a negative impact (see Infante \& Rancer, 1996). This does not appear to be the case in Presidential debates. All candidates will use verbally aggressive utterances. If verbal aggression were seen as a globally negative communication behavior in the political arena, no candidate having used more verbally aggressive utterances than their opponent would be victorious. While other factors have an impact on the election, the results of this study demonstrate that verbal aggression can be an effective communication behavior if used properly. In the political arena, properly can be defined as the use of congruity between verbal and nonverbal communication or the strategic use of enthymemes. This, in turn, leads to effective communication in Presidential debates.

The main implication of this study is that the findings provide further support for the theory that challengers will attack more frequently than the incumbents. Results from the current study demonstrate that regardless of the outcome of the election, challengers will use more verbally aggressive utterances than incumbents. The findings for the current study go further to provide support that challengers are allowed to use more negative campaign tactics, due to the fact that of the nine elections examined, five challengers won. If verbal aggression is seen as a detrimental communication behavior which hinders persuasion and credibility, then it should be that a candidate who uses significantly more verbally aggressive utterances than their opponents should not win an election. This is not the case, so it appears that the electorate is willing to allow challengers to attack more often, just so long as the challenger appears to be attacking the incumbent's record or issue stance and not the incumbent's character.

\section{Limitations}

There are few limitations to this study that need to be considered. The lack of accounting for other election-based variables could be a limitation of this study. While the goal of this study 
was not to predict elections, it was to gain a better understanding of how the use of verbal aggression in the Presidential debates impacts election. However, it is still important to note that other variables exist in election models (Markus, 1992; Nadeau \& Lewis-Beck, 2001). The use of only one debate per election could also be a limitation on the current study. Debates are held in different context and an examination of each of the debates per election could produce more significant results. Another limitation that could have hindered the results of this study was the lack of video copies of each debate in the study. An exhaustive search was conducted and the videos were deemed unattainable for this study. However, the absence of the videos could have impacted the results for Research Question One.

\section{Future Research}

The results of this study can be examined further in a variety of fashions. Since very little has been done to determine the impact of verbal aggression in the political field, research should continue to focus on how the strategic use of verbal aggression can impact not only elections, but Presidential approval and other Presidential variables (i.e., trust, leadership, and competence). As for election research, the focus should now turn to the impact that specific types of verbally aggressive utterances have on election outcomes. While this topic was briefly touched upon in the current study, future research needs to be done to determine if specific types of verbally aggressive utterances matter more to the electorate than the overall use verbal aggression. Research could examine the candidate characteristics that indicate those who are prone to use verbally aggressive utterances. Other predictors could include political affiliation, geographic region, age, closeness of the race, and characteristics of the debate watching audience. Results from the current study hint that verbal aggression may not completely be a trait but a strategic behavior geared toward persuading public opinion. Further research needs to examine how the 
same candidate uses verbally aggressive utterance when their status has changed (e.g. Clinton as the challenger in 1992 versus Clinton as the incumbent in 1996). It appears as if the controlling factor is candidate status (i.e., challenger or incumbent) and not trait verbal aggressiveness.

Further research needs to be conducted if this is in fact the case. 


\section{References}

Aden, R. C. (1994). The enthymeme as postmodern argument form: Condensed, mediated argument then and now. Argumentation and Advocacy, 31, 54-63.

Anderson, C. M., \& Martin, M. M. (1999). The relationship of argumentativeness and verbal aggressiveness to cohesion, consensus, and satisfaction in small groups. Communication Reports, 12, 21-32.

Beatty, M. J., Zelly, J. R., Dobos, J. A., \& Rudd, J. E. (1994). Fathers' trait verbal aggressiveness and argumentativeness as a predictors of adult sons' perceptions of fathers' sarcasm, criticism, and verbal aggressiveness. Communication Quarterly, 42, 407-415.

Benoit, W. L. (2004). Election outcome and topic of political campaign attacks. Southern Communication Journal, 69, 348-355.

Benoit, W. L., Blaney, J. R., \& Pier, P. M. (1998). Campaign '96: A functional analysis of acclaiming, attacking, and defending. New York: Praeger.

Benoit, W. L., Hansen, G. J., \& Verser, R. M. (2003). A meta-analysis of the effects of viewing U. S. Presidential debates. Communication Monographs, 70, 335-350.

Benoit, W. L., McKinney, M. S., \& Holbert, R. L. (2001). Beyond learning and persona: Extending the scope of presidential debate effects. Communication Monographs, 68, 259273.

Bitzer, L. (1959). Aristotle's enthymeme revised. Quarterly Journal of Speech, 45, 399-408.

Cobb, M. D., \& Kuklinski, J. H. (1997). Changing minds: Political arguments and political persuasion. American Journal of Political Science, 41, 88-121. 
Downs, V. C., Kaid, L. L., \& Ragan, S. (1990). The impact of argumentativeness and verbal aggression on communicator image: The exchange between George Bush and Dan Rather. West Journal of Speech Communication, 54, 99-112.

Erikson, R. S., MacKuen, M. B., \& Stimson, J. A. (2002). The Macro Polity. New York: Cambridge University Press.

Faucheux, R. A. (2002). Running for office: The strategies, techniques and messages modern political candidates need to win elections. New York: M. Evans \& Company.

Flanigan, W. H., \& Zingale, N. H. (2002). Political behavior of the American electorate (10 ${ }^{\text {th }}$ ed.). Washington: CQ Press.

Frey, L. R., Botan, C. H., \& Kreps, G. L. (2000). Investigating communication: An introduction to research methods. Needham Heights, MA: Allyn \& Bacon.

Glascock, J. (2003). Gender, race, and aggression in newer TV networks’ primetime programming. Communication Quarterly, 51, 90-100.

Glass, G. V., \& Hopkins, K. D. (1970). Statistical methods in education and psychology (2 ed.). Needham Heights, MA: Allyn and Bacon.

Guerrero, L. K., \& Dionisopoulos, G. N. (1990). Enthymematic solutions to the lockshin defection story: A case study in the repair of problematic narrative. Communication Studies, 41, 299-310.

Holbrook, T. H. (1996). Do campaigns matter? Thousand Oaks, CA: Sage.

Infante, D. A. (1987). Aggressiveness. In J. C. McCroskey \& J. A. Daly (Eds.), Personality and interpersonal communication (pp. 157-192). Newbury Park, CA: Sage. 
Infante, D. A., \& Gorden, W. I. (1985). Superiors' argumentativeness and verbal aggressiveness as predictors of subordinates' satisfaction. Human Communication Research, 12, 117125.

Infante, D. A., \& Rancer, A. S. (1982). A conceptualization and measure of argumentativeness. Journal of Personality Assessment, 46, 72-80.

Infante, D. A., \& Rancer, A. S. (1996). Argumentativeness and verbal aggressiveness: A review of recent theory and research. Communication Yearbook, 19, 319-351.

Infante, D. A., \& Wigley, C. J. (1986). Verbal aggressiveness: An interpersonal model and measure. Communication Monographs, 53, 61-69.

Infante, D. A., Chandler-Sabourin, T., Rudd, J. E., \& Shannon, E. A. (1990). Verbal aggression in violent and nonviolent martial disputes. Communication Quarterly, 38, 361-371.

Infante, D. A., Hartley, K. C., Martin, M. M., Higgins, M. A., Bruning, S. D., \& Hur, G. (1992). Initiating and reciprocating verbal aggression: Effects on credibility and credited valid arguments. Communication Studies, 43, 182-190.

Infante, D. A., Rancer, A. S., \& Ambler, M. (1994). Code book: Verbally aggressive messages in family and organizational contexts. Unpublished manuscript.

Infante, D. A., Riddle, B. L., Horvath, C. L., \& Tumlin, S. A. (1992). Verbal aggressiveness: Messages and reasons. Communication Quarterly, 40, 116-126.

Infante, D. A., Trebing, J. D., Shepherd, P. E., \& Seeds, D. E. (1984). The relationship of argumentativeness to verbal aggression. Southern Speech Communication Journal, 50, $67-77$.

Jackson, S., \& Jacobs, S. (1980). Structure of conversational argument: Pragmatic bases for the enthymeme. Quarterly Journal of Speech, 66, 251-265. 
Jamieson, K. H., Falk, E., \& Sherr, S. (1999). The enthymeme gap in the 1996 presidential campaign. PS: Political Science and Politics, 32, 12-16.

Kazoleas, D. (1993). The impact of argumentativeness on resistance to persuasion. Human Communication Research, 20, 118-137.

Levine, T. R., \& Badger, E. E. (1993). Argumentativeness and resistance to persuasion. Communication Reports, 6, 71-78.

Lewis-Beck, M. S., \& Rice, T. W. (1984). Forecasting presidential elections: A comparison of naïve models. Political Behavior, 6, 9-21.

Markus, G. B. (1992). The impact of personal and national economic conditions on presidential voting, 1956-1988. American Journal of Political Science, 36, 829-834.

Martin, M. M., Koehn, S. C., Weber, K., \& Mottet, T. P. (May, 1997). Verbal aggression on family sitcoms: Who said what to whom with what response. Paper presented at the annual meeting of the International Communication Association, Montreal, Canada.

Martin, M. M., Mottet, T. P., Weber, K., Koehn, S. C., \& Maffeo, V. P. (1998). The relationships of trait verbal aggressiveness and frequency of viewing and enjoyment of television sitcoms. Communication Research Reports, 15, 406-412.

Mayer, W. G. (1996). In defense of negative campaigning. Political Science Quarterly, 111, 437455.

Meyer, G., Roberto, A. J., Boster, F. J., \& Roberto, H. L. (2004). Assessing the Get Real About Violence curriculum: Process and outcome evaluation results and implication. Health Communication, 16, 451-475.

Miller, W. E., \& Shanks, J. M. (1996). The new American voter. Cambridge: Harvard University Press. 
Nadeau, R., \& Lewis-Beck, M. S. (2001). National economic voting in U.S. presidential elections. The Journal of Politics, 63, 159-181.

Neustadt, R. E. (1990). Presidential power and the modern presidents: The politics of leadership from Roosevelt to Reagan. New York: The Free Press.

Nichols, M. P. (1987). Aristotle's defense of rhetoric. Journal of Politics, 49, 657-677.

Onyekwere, E. O., Rubin, R. B., \& Infante, D. A. (1991). Interpersonal perception and communication satisfaction as a function of argumentativeness and ego-involvement. Communication Quarterly, 39, 35-47.

Perloff, R. M. (2003). The dynamics of persuasion: Communication and attitudes in the $21^{\text {st }}$ Century ( $2^{\text {nd }}$ ed.). Mahwah, NJ: Erlbaum.

Petty, R. E., \& Cacioppo, J. T. (1986). The elaboration likelihood model of persuasion. In L. Berkowitz (Ed.), Advances in experimental social psychology (Vol. 19, pp. 123-205). New York: Academic Press.

Pfau, M., \& Burgoon, M. (1989). The efficacy of issue and character attack message strategies in political campaign communication. Communication Reports, 2, 53-61.

Popkin, S. L. (1994). The reasoning voter: Communication and persuasion in presidential campaigns. Chicago: The University of Chicago Press.

Rancer, A. S. (1998). Argumentativeness. In J. C. McCroskey, J. A. Daly, M. M. Martin, \& M. J. Beatty (Eds.), Communication and personality: Trait perspectives. Cresskill, NJ: Hampton Press.

Rancer, A. S., Avtgis, T. A., Kosberg, R. L., \& Whitecap, V. C. (2000). A longitudinal assessment of trait argumentativeness and verbal aggressiveness between seventh and eighth grades. Communication Education, 49, 114-121. 
Rancer, A. S., Whitecap, V. G., Kosberg, R. L., \& Avtgis, T. A. (1997). Testing the efficacy of a communication training program to increase argumentativeness and argumentative behavior in adolescents. Communication Education, 46, 273-286.

Richmond, V. P., McCroskey, J. C., \& McCroskey, L. L. (1989). An investigation of selfperceived communication competence and personality orientations. Communication Research Reports, 6, 28-36.

Rocca, K. A., \& McCroskey, J. C. (1999). The interrelationship of student ratings of instructors' immediacy, verbal aggressiveness, homophily, and interpersonal attraction. Communication Education, 48, 308-316.

Rogan, R. G., \& La France, B. H. (2003). An examination of the relationship between verbal aggressiveness, conflict management strategies, and conflict interaction goals. Communication Quarterly, 51, 458-469.

Skaperdas, S., \& Grofman, B. (1995). Modeling negative campaigning. The American Political Science Review, 89, 49-61.

Tamborini, R., Chory-Assad, R. M., Lachlan, K., Westerman, D., \& Skalski, P. (May, 2005). Talking smack: Verbal aggression in professional wrestling. Paper presented at the annual meeting of the International Communication Association, New York, NY.

Venable, K. V., \& Martin, M. M. (1997). Argumentativeness and verbal aggressiveness in dating relationships. Journal of Social Behavior \& Personality, 12, 955-964.

Wattenberg, M. P., \& Brians, C. L. (1999). Negative campaign advertising: Demobilizer or mobilizer? The American Political Science Review, 93, 891-899.

Zulick, M. D. (1997). Generative rhetoric and public argument: A classical approach. Argumentation and Advocacy, 33, 109-119. 


\section{Appendix A}

Short-Form Version of the Infante and Rancer (1982) Argumentativeness Scale

Instructions: This questionnaire contains statements about arguing controversial issues. Indicate how often each statement is true for you personally by placing the appropriate number in the blank to the left of the statement. Use the following scale:

$$
\begin{gathered}
1=\text { almost never true } \\
2=\text { rarely true } \\
3=\text { occasionally true } \\
4=\text { often true } \\
5=\text { almost always true }
\end{gathered}
$$

1. While in an argument, I worry that the person I am arguing with will form a negative impression of me.

2. I am energetic and enthusiastic when I argue.

3. I enjoy a good argument over a controversial issue.

4. I prefer being with people who rarely disagree with me.

5. I enjoy defending my point of view on an issue.

6. When I finish arguing with some I feel nervous and upset.

7. I consider an argument an exciting intellectual challenge.

8. I find myself unable to think of effective points during an argument.

9. I have the ability to do well in an argument.

10. I try to avoid getting into arguments. 


\section{Appendix B}

Short-Form Version of the Infante and Wigley (1986) Verbal Aggressiveness Scale

Instructions: This survey is concerned with how we try to get people to comply with our wishes. Indicate how often each statement is true for you personally when you try to influence other person. Use the following scale:

$$
\begin{gathered}
1=\text { almost never true } \\
2=\text { rarely true } \\
3=\text { occasionally true } \\
4=\text { often true } \\
5=\text { almost always true }
\end{gathered}
$$
ideas.

1. I am extremely careful to avoid attacking individuals' intelligence when I attack their

2. When individuals are very stubborn, I use insults to soften their stubbornness.

3. I try very hard to avoid having other people feel bad about themselves when I try to influence them.

4. If individuals I am trying to influence really deserve it, I attack their character.

5. I try to make people feel good about themselves even when their ideas are stupid.

6. When people simply will not budge on a matter of importance, I lose my temper and say rather strong things to them.

7. When individuals insult me, I get a lot of pleasure out of really telling them off.

8. When I attack a persons' ideas, I try not to damage their self-concepts.

9. When I try to influence people, I make a great effort not to offend them.

10. When nothing seems to work in trying to influence others, I yell and scream in order to get some movement from them. 


\section{Appendix C}

\section{Demographic Questions}

Age:

Sex:

Male

Female

Did you vote in a previous election?

Yes

No

What is your registered political affiliation?

Democrat

Republican

Independent

Other

\section{Political Predispositions}

We hear a lot of talk these days about liberals and conservatives. Here is a 7-point scale on which the political views that people might hold are arranged from extremely liberal to extremely conservative. Where would you place yourself on this scale, or haven't you thought much about this?

1. Extremely Liberal

2. Liberal

3. Slightly Liberal

4. Moderate, Middle of the Road

5. Slightly Conservative

6. Extremely Conservative

7. DK; Haven't Thought Much About It

There have been three Presidential debates held this year. Which would apply to your watching of these debates?

1. Foreign Policy Debate, (date)

2. Townhall Debate, (date)

3. Domestic Policy Debate (date)

4. $\quad 1$ and 2

5. 1 and 3

6. 2 and 3

7. 1,2 , and 3 
If you viewed any of the debates above, what portion of the debates would you say best describes your viewing patterns?
1. Every Minute
2. Half or More
3. Half or Less
4. Opening or Closing Statements
5. Post Commentary 


\section{Appendix D}

Table 1: Candidate Mean and Standard Deviation

\begin{tabular}{llllr}
\hline Candidate & Year & Debate & Mean & Standard Deviation \\
\hline Nixon & 1960 & 1 of 4 & 26.10 & 10.04 \\
Kennedy & 1960 & 1 of 4 & 25.50 & 11.29 \\
Ford & 1976 & 3 of 3 & 16.10 & 7.26 \\
Carter & 1976 & 3 of 3 & 43.90 & 18.46 \\
Carter & 1980 & 1 of 1 & 31.50 & 11.00 \\
Reagan & 1980 & 1 of 1 & 45.80 & 17.00 \\
Reagan & 1984 & 2 of 2 & 17.70 & 12.45 \\
Mondale & 1984 & 2 of 2 & 51.20 & 24.67 \\
Bush & 1988 & 2 of 2 & 16.90 & 10.60 \\
Dukakis & 1988 & 2 of 2 & 54.50 & 21.36 \\
Bush & 1992 & 2 of 3 & 14.00 & 8.69 \\
Clinton & 1992 & 2 of 3 & 21.90 & 11.38 \\
Clinton & 1996 & 1 of 2 & 22.90 & 17.04 \\
Dole & 1996 & 1 of 2 & 53.00 & 24.43 \\
Gore & 2000 & 3 of 3 & 24.10 & 13.46 \\
G. W. Bush & 2000 & 3 of 3 & 24.30 & 14.06 \\
G. W. Bush & 2004 & 2 of 3 & 38.10 & 18.32 \\
Kerry & 2004 & 2 of 3 & 83.80 & 29.85 \\
\hline
\end{tabular}

Table 2: Incumbent Versus Challenger Point-Biserial Correlations

\begin{tabular}{llll}
\hline Race & Year & Point-Biserial & Variance Accounted \\
\hline Nixon-Kennedy & 1960 & .03 & $0 \%$ \\
Ford-Carter & 1976 & $-.72^{* * *}$ & $52 \%$ \\
Carter-Reagan & 1980 & $-.46^{*}$ & $21 \%$ \\
Reagan-Mondale & 1984 & $-.67^{* *}$ & $45 \%$ \\
Bush-Dukakis & 1988 & $-.75^{* * *}$ & $56 \%$ \\
Bush-Clinton & 1992 & -.37 & $14 \%$ \\
Clinton-Dole & 1996 & $-.60^{* *}$ & $36 \%$ \\
Gore-Bush & 2000 & -.01 & $0 \%$ \\
Bush-Kerry & 2004 & $-.70^{* * *}$ & $49 \%$ \\
\hline
\end{tabular}

Note: ${ }^{*} p<.05, * * p<.01, * * * p<.001$ 
Table 3: Winner Versus Loser Point Biserial Correlations

\begin{tabular}{lccc}
\hline Race & Year & Point-Biserial & Variance Accounted \\
\hline Nixon-Kennedy & 1960 & -.03 & $0 \%$ \\
Ford-Carter & 1976 & $.72^{* * *}$ & $52 \%$ \\
Carter-Reagan & 1980 & $.46^{*}$ & $21 \%$ \\
Reagan-Mondale & 1984 & $-.67^{* *}$ & $45 \%$ \\
Bush-Dukakis & 1988 & $-.75^{* * *}$ & $56 \%$ \\
Bush-Clinton & 1992 & .37 & $14 \%$ \\
Clinton-Dole & 1996 & $-.60^{* *}$ & $36 \%$ \\
Gore-Bush & 2000 & .01 & $0 \%$ \\
Bush-Kerry & 2004 & $-.70^{* * *}$ & $49 \%$ \\
\hline
\end{tabular}

Note: $* p<.05,{ }^{* *} p<.01,{ }^{* * *} p<.001$

Table 4: Candidate Comparisons for Written Versus Video Coding of the Debates

\begin{tabular}{llll}
\hline Race & Year & $T$ & $P$ \\
\hline Reagan & 1984 & -1.71 & 0.10 \\
Mondale & 1984 & -0.95 & 0.35 \\
Bush & 1988 & -1.67 & 0.12 \\
Dukakis & 1988 & -1.19 & 0.24 \\
Clinton & 1996 & -1.15 & 0.26 \\
Dole & 1996 & -1.23 & 0.23 \\
G. W. Bush & 2004 & -2.05 & 0.07 \\
Kerry & 2004 & -0.99 & 0.34 \\
\hline
\end{tabular}




\section{Footnotes}

${ }^{1}$ For the purpose of this study, the definition of incumbent will be the party of the incumbent president (Markus, 1992).

${ }^{2}$ There were no presidential debates in 1964, 1968, or 1972.

${ }^{3}$ Video copies were obtained for 1984, 1988, 1996, 2004 (1980 was received but the tape was damaged). In an effort to obtain video copies of the four missing debates, exhaustive searchers were undertaken. The efforts resulted in the cost of obtaining the videos to be prohibitive. As such they were excluded from the analyses. 